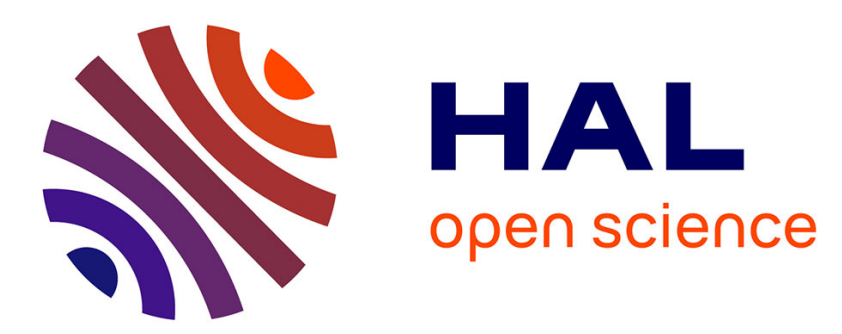

\title{
Influence of the process design on the control strategy: application in electropneumatic field
}

\author{
Xavier Brun, Daniel Thomasset, Eric Bideaux
}

\section{To cite this version:}

Xavier Brun, Daniel Thomasset, Eric Bideaux. Influence of the process design on the control strategy: application in electropneumatic field. Control Engineering Practice, 2002, 10 (7), pp.727-735. 10.1016/S0967-0661(02)00030-8 . hal-00140640

\section{HAL Id: hal-00140640 \\ https://hal.science/hal-00140640}

Submitted on 2 Apr 2019

HAL is a multi-disciplinary open access archive for the deposit and dissemination of scientific research documents, whether they are published or not. The documents may come from teaching and research institutions in France or abroad, or from public or private research centers.
L'archive ouverte pluridisciplinaire HAL, est destinée au dépôt et à la diffusion de documents scientifiques de niveau recherche, publiés ou non, émanant des établissements d'enseignement et de recherche français ou étrangers, des laboratoires publics ou privés. 


\title{
INFLUENCE OF THE PROCESS DESIGN ON THE CONTROL STRATEGY: APPLICATION IN ELECTROPNEUMATIC FIELD
}

\author{
X. Brun*, D. Thomasset, E. Bideaux \\ Laboratoire d'Automatique Industrielle, INSA Lyon, Bâtiment Saint Exupéry, 25 Avenue Jean Capelle, 69621 Villeurbanne, France
}

\begin{abstract}
This article proposes an example of electropneumatic system where the architecture of the process is modified to respect both the specifications for position and velocity tracking and a criterion concerning the energy consumption. Experimental results are compared and analyzed using an industrial bench test. For this, a complete model of the system is presented, and two kinds of nonlinear control laws are developed, a monovariable and a multivariable based on the flatness theory.
\end{abstract}

Keywords: $\quad$ Design system; Nonlinear control; Pneumatic systems; Efficiency enhancement

\section{Introduction}

The design of a modern process needs a good co-ordination between different engineers specialized in specific fields. More and more often, the new industrial products are born with advanced technologies in electronics, mechanics, materials knowledge, computing and with evolved sensors and actuators. Very often, after the product creation stage comes the need for a choice of control. For this, a good background and understanding of the modern automatic theories is required. It is then necessary to choose an appropriate control strategy to obtain good performances in term of safety, stability, repeatability and accuracy. Even though during the last century the traditional solution was essentially a P.I.D. structure, nowadays, modern control laws are implemented.

The goal of this paper is to show the influence of the control strategy on the system design. Indeed, if the process design influences the choice of the control law, it would be interesting that the people who 
choose the control strategy could influence the design. This idea will be developed in this paper in the context of an electropneumatic system.

In the first section two different kinds of electropneumatic positioning systems will be presented and modelled. The following section elaborates two kinds of control laws for each system. The choice of a nonlinear control strategy (Isidori, 1989; Fliess, Levine, Martin, \& Rouchon, 1995) will be argued. The last section will be devoted to the experimental results. Both sets of results will be compared following an industrial benchmark. At the end, the aim is to conclude on the influence of the process design on the control strategy.

\section{Two kinds of electropneumatic positioning systems}

This part presents two different systems for electropneumatic position tracking. Both of them use the following structure: servo-valve / actuator / mass in translation. In each case the cylinder and the moving mass are the same, only the first power stage is modified (see figure 1). The actuator under consideration is an in-line electropneumatic cylinder using a simple rod $(32 / 20 \mathrm{~mm})$ with a stroke equal to $500 \mathrm{~mm}$. The rod is connected to one side of a carriage and drives an inertial load on guiding rails. The total mass (piston, rod and carriage) is equal to $17 \mathrm{~kg}$. The difference between each system concerns how the mass flow rate is modulated in each actuator chamber. In the first case (figure 1a) a five-way proportional servo-valve is used, in the second case (figure $\mathbf{1 b}$ ), two three way proportional servo-valves are implemented. All components have similar technology that consists of a spool sliding in a sleeve, actuated directly by proportional solenoid acting against a spring. A state feedback control of servo-valve spool position is used in order to decrease the effects of hysteresis and to increase the bandwidth of the servo-valve. So in the first case only one control is available, but in the second case the structure has one more degree of freedom. This property could be interesting in a case of multi-objectives. 
The electropneumatic system model can be obtained using classical assumptions (Shearer, 1956): considering the pressure behavior in a chamber with variable volume and the mechanical equation including pressure force, viscous friction $(b . v)$, dry friction $\left(F_{f}\right)$ and an external force $\left(F_{\text {ext }}\right)$ due to atmospheric pressure. Using the theory of multi-scale systems, the dynamics of the servo-valves may be neglected (Bouhal, 1994). So, the model can be reduced to a static one described by two relationships $q_{m} P\left(u_{P}, p_{P}\right)$ and $q_{m}{ }^{N}\left(u_{N}, p_{N}\right)$ between the mass flow rates $q_{m} P$ and $q_{m}$, the input voltages $u_{P}$ and $u_{N}$, and the output pressures $p_{P}$ and $p_{N}$.

The state model is given by equation (1):

$$
\left\{\begin{array}{l}
\frac{d p_{P}}{d t}=\frac{k \cdot r \cdot T_{S}}{V_{P}(y)}\left[q_{m}{ }_{P}\left(u_{P}, p_{P}\right)-\frac{S_{P}}{r T_{S}} \cdot p_{P} \cdot v\right] \\
\frac{d p_{N}}{d t}=\frac{k \cdot r \cdot T_{S}}{V_{N}(y)}\left[q_{m}\left(u_{N}, p_{N}\right)+\frac{S_{N}}{r T_{S}} \cdot p_{N} \cdot v\right] \\
\frac{d v}{d t}=\frac{1}{M}\left[S_{P} \cdot p_{P}-S_{N} \cdot p_{N}-b \cdot v-F_{f}-F_{e x t}\right] \\
\frac{d y}{d t}=v
\end{array}\right.
$$

Where $\left\{\begin{array}{l}V_{P}(y)=V_{P}(0)+S_{P} y \\ V_{N}(y)=V_{N}(0)-S_{N} y\end{array}\right.$ with $\left\{\begin{array}{l}V_{P}(0)=V_{D P}+S_{P} \frac{\text { Stroke }}{2} \\ V_{N}(0)=V_{D N}+S_{N} \frac{\text { Stroke }}{2}\end{array}\right.$ are the piping volumes of the chambers for the zero position and $V_{D(P \text { or } N)}$ are dead volumes present on each of the extremities of the piston.

In the case of a nonlinear control synthesis, the theory that respects Isidori's work (Isidori, 1989) requires that the model must be a linear function of the control input, in order to obtain an explicit form of the control law. Therefore the mass flow rate characterization obtained from experimental measurements (see figure 2) was approximated by polynomial function (Belgharbi, Thomasset, Scavarda \& Sesmat, 1999) affine in control (see equation (2)). 
$\left\{\begin{array}{l}q_{m}\left(u_{P}, p_{P}\right)=\varphi\left(p_{P}\right)+\psi\left(p_{P}, \operatorname{sgn}\left(\Gamma\left(u_{P}\right)\right)\right) \cdot \Gamma\left(u_{P}\right) \\ q_{m}\left(u_{N}, p_{N}\right)=\varphi\left(p_{N}\right)+\psi\left(p_{N}, \operatorname{sgn}\left(\Gamma\left(u_{N}\right)\right)\right) \cdot \Gamma\left(u_{N}\right)\end{array}\right.$

$\varphi($.$) and \psi($.$) are polynomials functions and \Gamma($.$) is an odd function.$

With two inputs $\Gamma\left(u_{P}\right)$ and $\Gamma\left(u_{N}\right)$, the nonlinear model of the system on figure $\mathbf{1 b}$ has the following form: $\underline{\dot{x}}=f(\underline{x})+G(\underline{x}) \cdot \underline{U} \quad$ where $f(x), G(\underline{x})$ and $\underline{U}$ are given by relations (3).

$\underline{x}=\left[\begin{array}{c}p_{P} \\ p_{N} \\ v \\ y\end{array}\right] \quad f(\underline{x})=\left(\begin{array}{c}\frac{k r T_{s}}{V_{P}(y)}\left[\varphi\left(p_{P}\right)-\frac{S_{P}}{r T_{s}} p_{P} v\right] \\ \frac{k r T_{s}}{V_{N}(y)}\left[\varphi\left(p_{N}\right)+\frac{S_{N}}{r T_{s}} p_{N} v\right] \\ \frac{1}{M}\left[S_{P} p_{P}-S_{N} p_{N}-b v-F_{f}-F_{e x t}\right] \\ v\end{array}\right) \quad G(\underline{x})=\left(\begin{array}{cc}\frac{k \cdot r \cdot T_{S}}{V_{P}(y)} \cdot \mu\left(p_{P}, s g n\left(U_{P}\right)\right) & 0 \\ 0 & \frac{k \cdot r \cdot T_{S}}{V_{N}(y)} \cdot \psi \cdot\left(p_{N}, \operatorname{sgn}\left(U_{N}\right)\right) \\ 0 \\ 0\end{array}\right) \quad \underline{U}=\left(\begin{array}{l}U_{P} \\ U_{N}\end{array}\right)=\left(\begin{array}{l}\Gamma\left(u_{P}\right) \\ \Gamma\left(u_{N}\right)\end{array}\right)$

Furthermore in the case of one five way servo-valve (figure 1a) the model is given by relation (5) which is in the nonlinear affine form (equation (4)):

$\underline{\dot{x}}=f(\underline{x})+g(\underline{x}) \times U$

$U=\Gamma(u) \quad g(\underline{x})=\left(\begin{array}{c}\frac{k r T_{s}}{V_{P}(y)} \psi\left(p_{P}, \operatorname{sgn}(U)\right) \\ -\frac{k r T_{s}}{V_{N}(y)} \psi\left(p_{N}, \operatorname{sgn}(-U)\right) \\ 0 \\ 0\end{array}\right)$ 


\section{Two kinds of nonlinear control strategy}

Nowadays electropneumatic or electrohydraulic systems are controlled in position tracking (Edge, 1997; Sohl \& Bobrow, 1999; Brun, Thomasset, Sesmat \& Scavarda, 1999a; Liu \& Daley 2000; Bouri \& Thomasset 2001) or in force tracking (Alleyne \& Liu, 1999; Niksefat \& Sepehri 2000; Alleyne \& Liu 2000).

In the case of mono-criteria, it seems more interesting to choose a system with one five way servovalve. In fact this structure is more attractive in cost, regarding the equipment. Very often the constructor proposes two three-way servo-valves which seems equivalent to one five way when they are controlled with input of opposite signs. But this assumes that they are identical and symmetrical. This strategy (two servo-valves and only one control law with opposite sign) is more classical in industrial process. In fact, it is a bad strategy because it does not use the two degrees of freedom available on the design.

With the system with two three-way servo-valves it is possible to control two different trajectories. For example it seems useful to control position and stiffness for compliant tasks, or why not track a desired position with minimum energy consumption?

The two following parts present a control strategy for two different objectives:

- A nonlinear monovariable control law developed for tracking position.

- A nonlinear multivariable control law developed for tracking position and energy saving.

\subsection{Nonlinear monovariable control strategy}

A convenient way to control the model (4) is to use the nonlinear linearizing control law (Isidori 1989), which theoretically transforms the closed loop system into two parts. The first part consists of a cascade of $\rho$ integrators and the second is an unobservable subsystem of dimension $(n-\rho)$ ( $\rho$ is the relative order of the output, $n$ is the system order). The single output is the position: $h(\underline{x})=y$ 
A simple calculation shows that for the system under study, the characteristic number is equal to three. In the single input single output case, the linearizing nonlinear control is given by (Brun \& Thomasset, 2000):

$U=\frac{1}{L_{g} L_{f}^{2} h}\left(-L_{f}^{3} h+w\right)$ with $\left\{\begin{array}{l}L_{f}^{3} h=\frac{S_{P}}{M} \frac{k r T_{S}}{V_{P}(y)}\left[\varphi\left(p_{P}\right)-\frac{S_{P}}{r T_{s}} p_{P} v\right]-\frac{S_{N}}{M} \frac{k r T_{s}}{V_{N}(y)}\left[\varphi\left(p_{N}\right)+\frac{S_{N}}{r T_{S}} p_{N} v\right] \\ L_{g} L_{f}^{2} h=\frac{S_{P}}{M} \frac{k r T_{S}}{V_{P}(y)} \psi\left(p_{P}, \operatorname{sgn}(U)\right)+\frac{S_{N}}{M} \frac{k r T_{s}}{V_{N}(y)} \psi\left(p_{N}, \operatorname{sgn}(-U)\right)\end{array}\right.$

It is important to note that $L_{g} L_{f}^{2} h$ is always strictly positive. So $U$ has the same sign as $\left(-L_{f}^{3} h+w\right)$. By definition, $L_{f}^{3} h$ and $w$ are independent of $U$ (see equations (6) and (7)). Consequently, the control law is not implicit. This explains the choice of the function $\varphi$, independent of $U$, in the mass flow rate expression of equation (2).

The second feedback law, which fixes the dynamic behavior of the state tracking errors, is obtained with the reference model:

$w=j^{d}-K_{y}\left(y^{d}-y\right)-K_{v}\left(v^{d}-v\right)-K_{a}\left(a^{d}-a\right)$

The nonlinear control applied to the system is shown in figure $\mathbf{3}$ and may be written as in equation (8).

$u=\Gamma^{-1}\left(\frac{1}{L_{g} L_{f}^{2} h}\left(-L_{f}^{3} h+j^{d}-K_{y}\left(y^{d}-y\right)-K_{v}\left(v^{d}-v\right)-K_{a}\left(a^{d}-a\right)\right)\right)$

The validity of the control law depends on the stability of the unobservable subsystem of dimension one. It is very difficult to obtain results about the global stability of the residual dynamic but in the physical domain the local stability has been proved (Brun, Belgharbi, Sesmat, Thomasset \& Scavarda, 1999a). 


\section{Choice of desired output}

In this paper the control strategy relates to in tracking the desired position with minimum energy consumption. For this, a first study in simulation has been led (Brun, Thomasset, Sesmat \& Scavarda, 1999b) to evaluate the possibility to improve the efficiency with an appropriate supplementary desired trajectory.

To reduce the consumed energy, it is possible to decrease the mass flow rate delivered by each servovalve. For this a study of the static mass flow rate characteristics giving by figure $\mathbf{4}$ could help to choose the appropriate desired trajectory.

To reduced the mass flow rate, two aspects are very important:

- the values of the control signal must be small (as shown in the circle on figure 4a).

- the pressure variation must be between 1 and 3 bar absolute (as shown in the circle on figure 4b).

So the choice is about elaborating a desired pressure trajectory in chamber P. This solution is easy to implement and does not need an additional sensor. In order to do that, an optimization algorithm has been developed.

A second important argument that led us to choose the pressure as the second output, is its property of flatness (Fliess et al., 1995). Indeed, position and pressure are flat outputs (see appendix B), and so the complexity of implementing the nonlinear control law is reduced as shown in the last section of this paragraph. 


\section{Optimization algorithm}

The pneumatic energy delivered by the compressor which enters the actuator through each servo-valve are given by equation (9). This energy is denoted $W_{P N E U}^{i n} ; H_{P_{i n}}$ and $H_{N_{i n}}$ are the enthalpy mass flow rate delivered respectively inside chambers $\mathrm{P}$ and $\mathrm{N}$ of the actuator. $\mathrm{c}_{\mathrm{p}}$ is the constant pressure specific heat and $\mathrm{T}_{\mathrm{S}}$ is the temperature supply (assumed constant).

$W_{P N E U}^{i n}=\int_{0}^{T_{\text {cycle }}}\left[H_{P_{\text {in }}}(t)+H_{N_{\text {in }}}(t)\right] d t$ with $\left\{\begin{array}{l}H_{P_{\text {in }}}(t)=q_{m} P\left(u_{P}(t), p_{P}(t)\right) \mathrm{c}_{p} T_{S} \\ H_{N_{\text {in }}}(t)=q_{m} N\left(u_{N}(t), p_{N}(t)\right) \mathrm{c}_{p} T_{S}\end{array}\right.$

The flatness property means that the control law could be expressed from the desired trajectories and its successive derivations. So with this result and using equation (2) and (9) the enthalpy mass flow rate can be expressed only with desired position, velocity, acceleration, jerk (imposed by the industrial specifications) pressure in one chamber and first derivation of this pressure as shown the equation (10).

$$
H_{P_{i n}}(t)+H_{N_{\text {in }}}(t)=\Lambda\left(y^{d}, v^{d}, a^{d}, j^{d}, p_{P}^{d}, d p_{P}^{d} / d t\right)
$$

This function $\Lambda\left(y^{d}, v^{d}, a^{d}, j^{d}, p_{P}^{d}, d p_{P}^{d} / d t\right)$ has been optimized with the constraint given by relation $(11$ and with the desired trajectories in position and successive derivatives given by figure $\mathbf{5}$.

$$
\left\{\begin{array}{l}
10^{5} \mathrm{~Pa} \leq p_{P} \leq 7.10^{5} \mathrm{~Pa} \\
10^{5} \mathrm{~Pa} \leq p_{N} \leq 7.10^{5} \mathrm{~Pa} \\
-10 \text { volt } \leq u_{P} \leq 10 \text { volt } \\
-10 \text { volt } \leq u_{N} \leq 10 \text { volt }
\end{array}\right.
$$


The results obtained after optimization with constraints are presented on the figure $\mathbf{6}$. The aim is to reduce the pressure in chamber $\mathrm{P}$. So the desired pressure during static conditions is equal to 1.54 bar absolute. It goes up to 4.21 bar absolute during the extension stroke and it is equal to 1.20 bar absolute during the retraction stroke.

\section{Nonlinear multivariable synthesis}

So the two chosen outputs are the pressure in chamber $P$ and the position:

$$
h(\underline{x})=\left(\begin{array}{c}
h_{1}(\underline{x}) \\
h_{2}(\underline{x})
\end{array}\right)=\left(\begin{array}{c}
p_{P} \\
y
\end{array}\right)
$$

The characteristic number associated to the pressure $p_{P}$ and the position are respectively one and three. Thus, the sum is equal to the dimension of the system. This is sufficient to affirm that the system is differentially flat (Fliess et al., 1995). Due to the flatness definition, the inputs can be written as functions of outputs and a finite number (equal to the characteristic number) of their time derivatives. A direct way to obtain the nonlinear linearizing control laws which decouples the system consists in using the expressions of $d p_{P}^{d} / d t$ and $j^{d}$ and inverting them. The result is given by equation (13). With the two previous control inputs $u_{P}$ and $u_{N}$, the nonlinear electropneumatic model is transformed into two linear models, one simple integrator and one triple integrator. Classic feedback laws (see equation (14)) can stabilize each of them. In this case the global stability is obvious. This is one of the main advantages of flatness. 


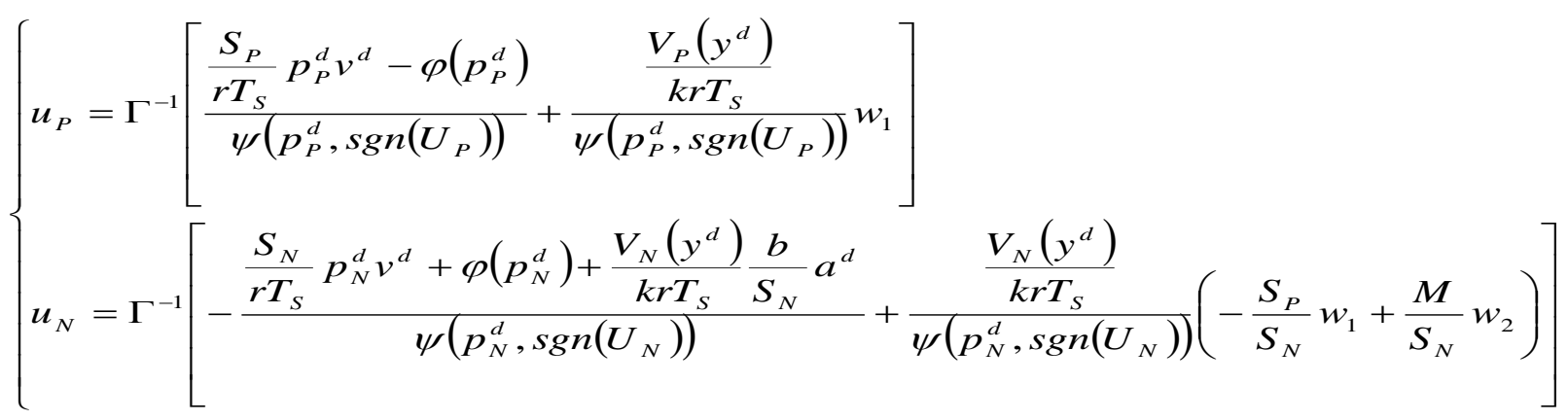

With $\quad p_{N}^{d}=\frac{1}{S_{N}}\left(S_{P} p_{P}^{d}-b v^{d}-F_{f}-F_{e x t}-M a^{d}\right)$

$$
\left\{\begin{array}{l}
w_{1}=\frac{d p_{P}^{d}}{d t}-K_{p_{P}}\left(p_{P}-p_{P}^{d}\right) \\
w_{2}=j^{d}-K_{a}\left(a-a^{d}\right)-K_{v}\left(v-v^{d}\right)-K_{y}\left(y-y^{d}\right)
\end{array}\right.
$$

\section{Experimental results}

The experimental results are presented in term of repeatability. So in this section each curves presents a mean value obtained after thirty tests. The standard deviation, mean and maximum values are calculated in each position and presented in the tables $\mathbf{1}$ and $\mathbf{2}$ for each control strategy. In the aim to show the performances of each control law under static and dynamic conditions, the standard deviations are calculated in each phase. The two tables show the better results obtain during static conditions. In case of monovariable control law the standard deviation is less than $0.1 \mathrm{~mm}$ with the other control method this value is near to $0.5 \mathrm{~mm}$. In general the results obtained with multivariable control law are better for velocity tracking and less satisfactory in position tracking (see tables $\mathbf{1}$ and $\mathbf{2}$ and figure $\mathbf{8}$ ).

As explain in section 3.2, the gain in terms of energy consumption depends of two parameters, which are the control signal and the pressure evolution. 
- Considering the figure 9, the multivariable control law is smoother than the monovariable one, which is a good property from an energetical efficiency point of view. Indeed, when the control signal increases, supply energy is used. And when the control signals decreases, the pneumatic energy goes to the exhaust. So control signal oscillations lead to bad efficiency.

- The figure $\mathbf{1 0}$ proves the reduced pressures in each chamber $\mathrm{P}$ and $\mathrm{N}$ obtained with multivariable control strategy. This method seems to lead to a real gain in energy terms and permits to modify the stiffness, but this concerns another study conducted in parallel in the laboratory.

Considering the mass flow rate characteristics (in figure 2), the experimental results in pressure (figure 10), the control signals (figure 9), and including the dynamics of the servo-valves, it is possible to reconstruct the mass flow rate delivered by the two servo-valves during the global movement. Considering that the equilibrium point on the start is the same than on the final, the total energy delivered by the compressor is equal to the integral of this reconstructed mass flow rate multiplied by a constant coefficient (see equation 9). The numerical results obtained show an improvement of $29 \%$ in term of energy delivered inside the cylinder with the multivariable non linear control.

\section{Conclusions}

This paper presents an example of electropneumatic system, where the control specialist chooses to act on the structure before working on an elaborate strategy of control. This study has been proved the importance of including the control specification during the design. Nowadays, more and more new products are developed including design, process architecture, choice of the structure actuators, place of sensors, sizing of component and control strategy. This approach permits to satisfactory link the specifications with other objectives, which could be important in term of economical improvement. It is important to note that the supplementary specifications could be obtained without a degradation of the desired specifications. 
Considering the electropneumatic field, the main objective concerns the tracking in term of position and velocity. The proposed approach consists of increasing the number of power modulators to obtain a supplementary degree of freedom and so to respect the imposed specifications and to reduce the energy consumption. The experimental results obtained lead to a similar behaviour in terms of position or velocity tracking, but the system with two servo-valves leads to a better efficiency in term of energy consumption. The next step will consists of comparing the cost due to the supplementary servo-valve with the gain due to energy saving. These methods could be also very interesting in electrohydraulic (oil or water) fields.

Another important aspect of this strategy concerns the stability. As noted in section 3.1 only the local asymptotic stability of the system with nonlinear control law in monovariable case has be proved (Brun 1999a). In case of multivariable nonlinear control, the flatness of the system leads to a global linearization and to a global stability of the closed loop system. 


\section{Appendix A. Nomenclature}

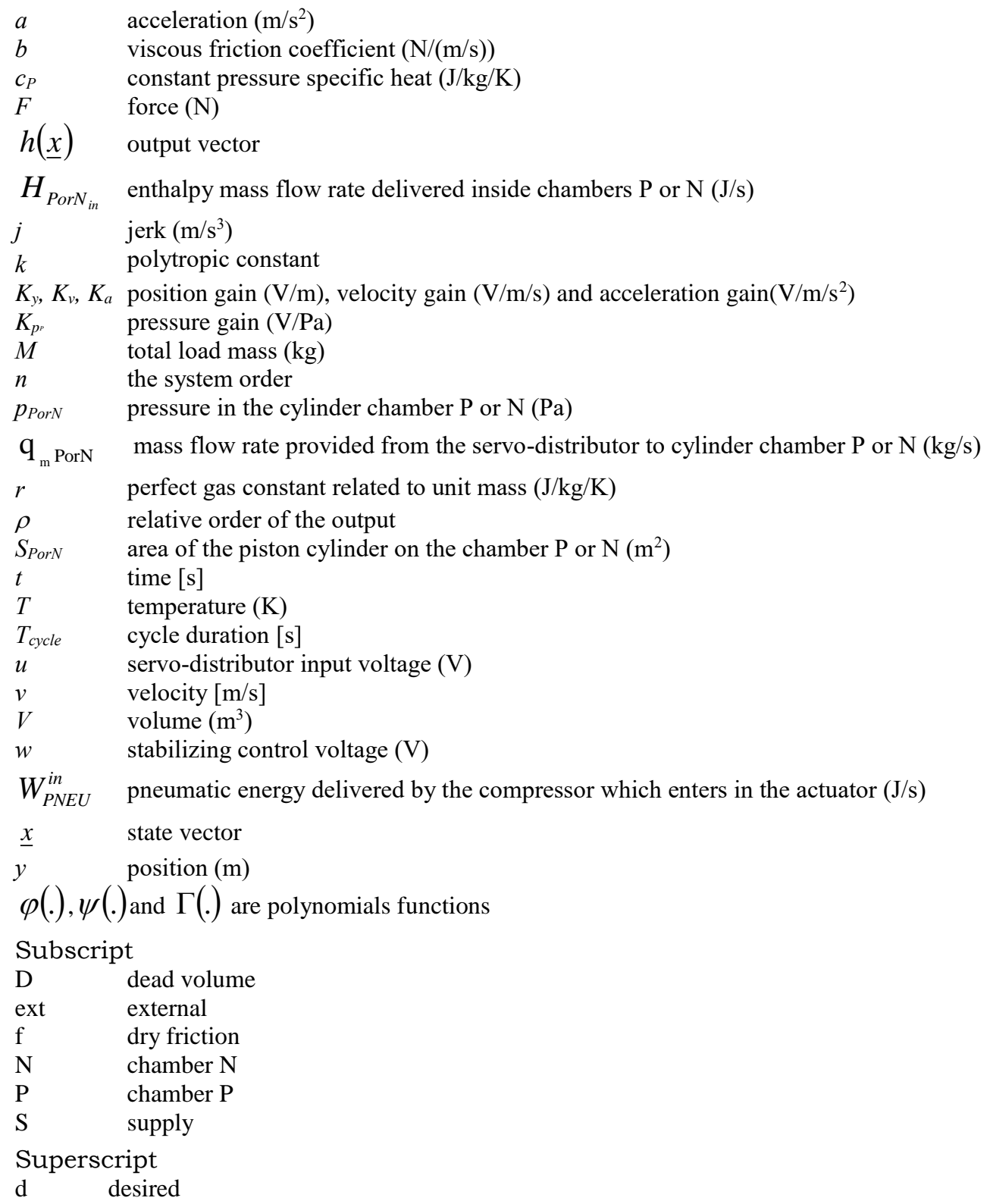

\section{Appendix B. Brief summary about flatness}

One of the classes of systems for which trajectory generation is particularly easy are so-called differentially flat systems (Fliess et al., 1995). Roughly speaking, a system is differentially flat if we can find a set of outputs (equal in number to the number of inputs) such that all states and inputs can be determined from these outputs without integration. More precisely, if the system has states $x \in \mathfrak{R}^{n}$, and inputs $u \in \mathfrak{R}^{m}$ then the system is flat if it is possible to can find outputs $y \in \mathfrak{R}^{m}$ of the form $y=y\left(x, u, \dot{u}, \ldots, u^{(p)}\right)$, such that: $x=x\left(y, \dot{y}, \ldots, y^{(q)}\right)$ and $u=u\left(y, \dot{y}, \ldots, y^{(q)}\right)$

The equation (13) explains why the pressure and the position have the property of flatness. It can be resumed by the following relations:

$$
\left\{\begin{array}{l}
u_{P}=f_{1}\left(y^{d}, v^{d}, p_{P}^{d}, \frac{d p_{P}^{d}}{d t}\right) \\
u_{N}=f_{2}\left(y^{d}, v^{d}, a^{d}, j^{d}, p_{P}^{d}, \frac{d p_{P}^{d}}{d t}\right)
\end{array}\right.
$$




\section{References}

Alleyne, A., \& Liu, R. (1999) On the limitations of force tracking control for hydraulic servosystems. ASME Journal Dynamic System Measurement and Control, 121 (2), 184-190.

Alleyne, A., \& Liu, R. (2000) Systematic control of a class of nonlinear systems with application to electrohydraulic cylinder pressure control. IEEE Trans. on Control Systems Technology, 8 (4), 623-634.

Belgharbi, M., Thomasset, D., Scavarda, S., \& Sesmat, S. (1999) Analytical model of the flow stage of a pneumatic servo-distributor for simulation and nonlinear control.., Proceedings of the Sixth Scandinavian International Conference on Fluid Power, SICFP'99 (pp. 847-860).Tampere, Finland.

Bouhal, A. (1994) Contribution à la commande linéaire et non linéaire adaptative des systèmes électropneumatiques. Ph.D. Thesis : Science.: INSA de Lyon.

Bouri, M., \& Thomasset, D. (2001) Sliding control of an electropneumatic actuator using an integral switching surface, Journal of Systems and Control Engineering, 9(2), 368-375.

Brun, X., Belgharbi, M., Sesmat, S., Thomasset, D., \& Scavarda, S. (1999a) Control of an electropneumatic actuator, comparison between some linear and nonlinear control laws. Journal of Systems and Control Engineering, 213 (I5), 387-406.

Brun, X., Thomasset, D., Sesmat, \& S., Scavarda, S. (1999b) Limited energy consumption in positioning control of electropneumatic actuator. Bath Workshop on Power Transmission \& Motion Control (pp 199211). Bath, England.

Brun, X., \& Thomasset, D. (2000) Choice of control law in electropneumatic. Expertise using an industrial benchmark and some new trends. $39^{\text {th }}$ IEEE Conference on Decision and Control (pp 1323-1328, [CD Rom], ref CD009702). Sydney, Australia

Edge, K.A. (1997) The control of fluid power systems - responding to the challenge. Journal of Systems and Control Engineering, 211(12), 91-110.

Fliess, M., Levine, J., Martin, P., \& Rouchon, P. (1995) Flatness and defect of non-linear systems : introductory, theory and applications. International Journal of Control, 61, 1327-1361.

Isidori, A., (1989) Nonlinear control systems. New York : Springer Verlag, $2^{\text {nd }}$ edition, 479 p.

Liu, G.P., \& Daley, S. (2000) Optimal-tuning nonlinear PID control of hydraulic systems. Control Engineering Practice, 8(9), 1045-1053.

Niksefat, N., \& Sepehri, N. (2000) Design and experimental evaluation of a robust force controller for an electro-hydraulic actuator via quantitative feedback theory. Control Eng. Practice, 8(12), 1335-1345.

Shearer, J.L. (1956) Study of pneumatic processes in the continuous control of motion with compressed air. Parts I and II. Trans. Am. Soc. Mech. Eng., 78, 233-249.

Sohl, G.A, \& Bobrow, J.E. (1999) Experiments and Simulations on the nonlinear Control of a Hydraulic Servosystem. IEEE Transactions on Control Systems Technology, 7(2), 238-247. 

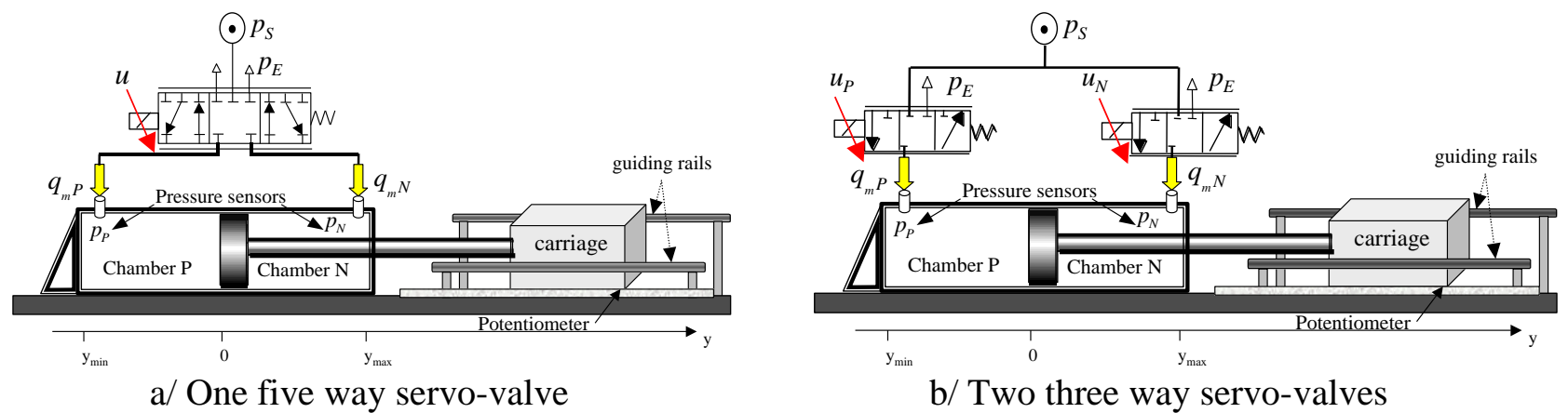

Figure 1: Two kinds of electropneumatic process designs

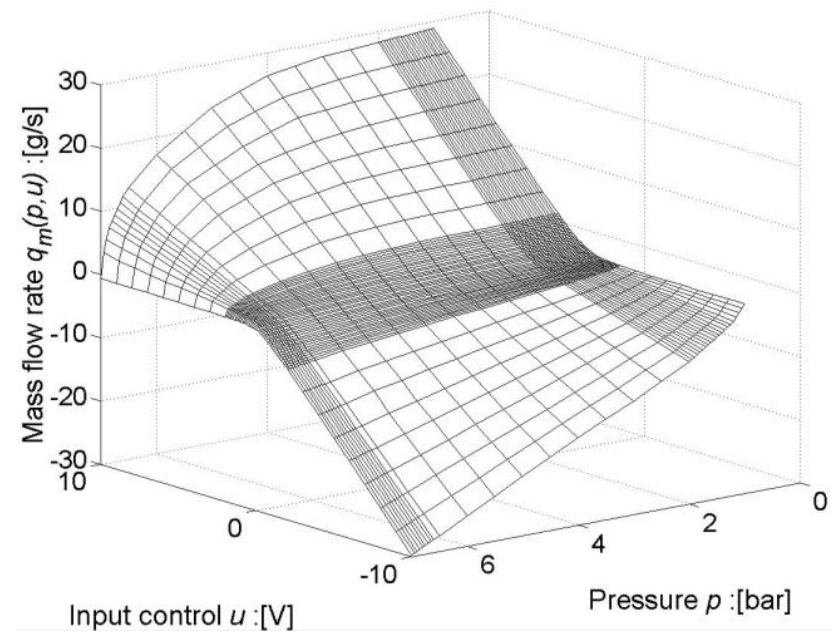

Figure 2: Servo-valve static characteristics

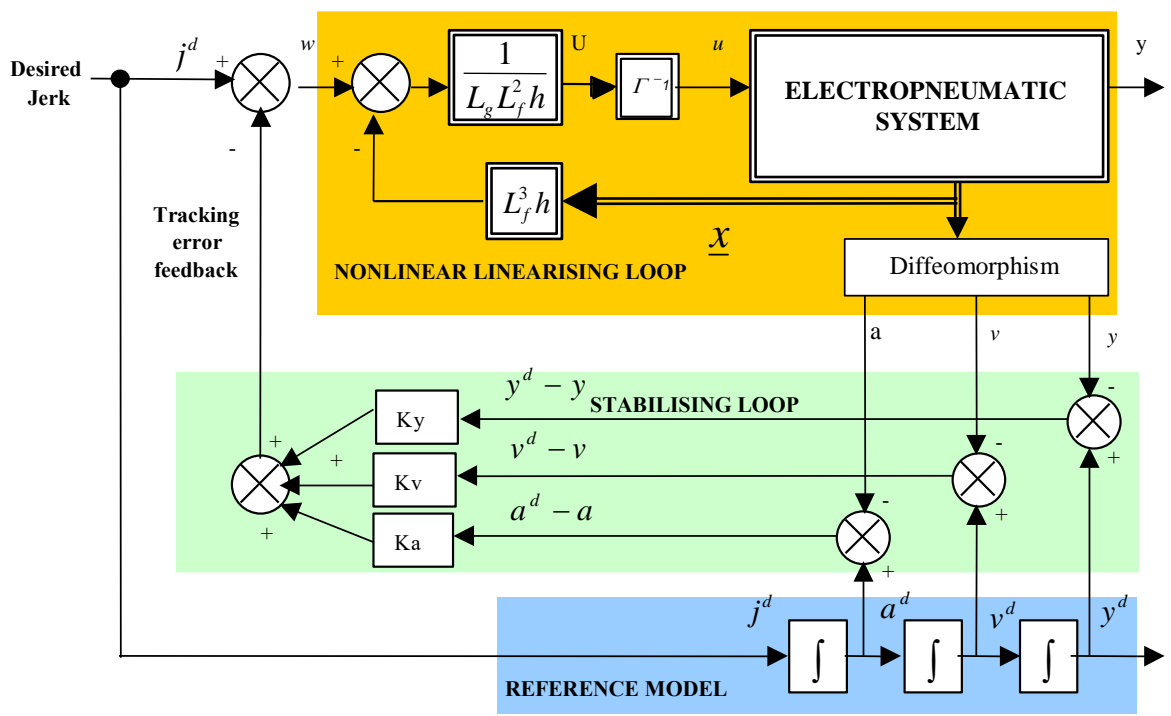

Figure 3: Principle of nonlinear monovariable control law 


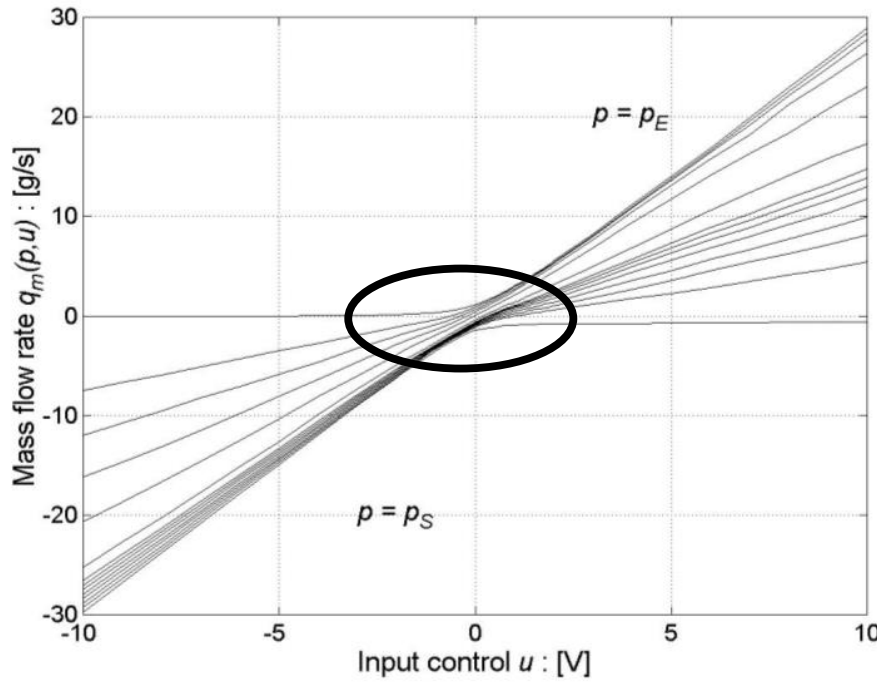

a/ Mass flow rate gain characteristic curves

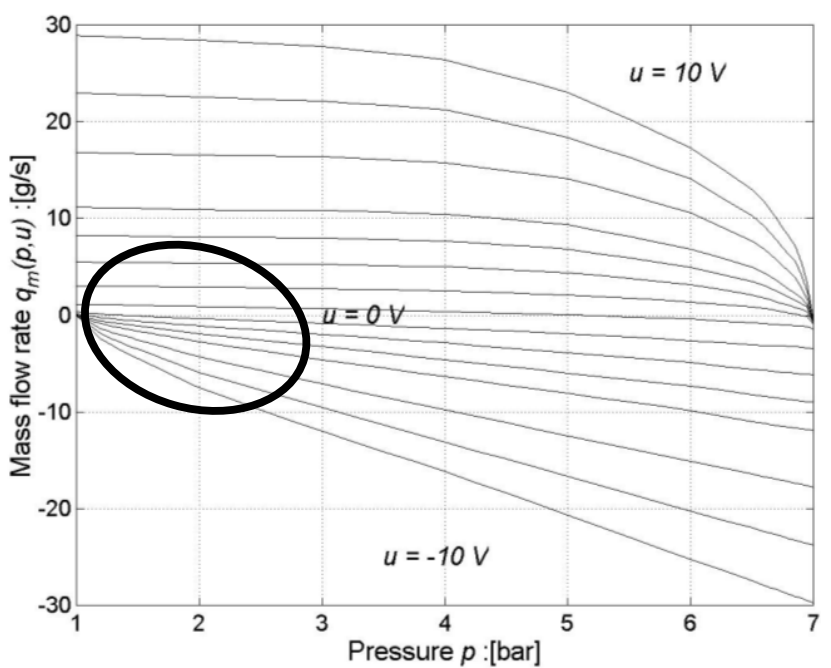

b/ Mass flow rate characteristic curves

Figure 4: Mass flow rate measurements

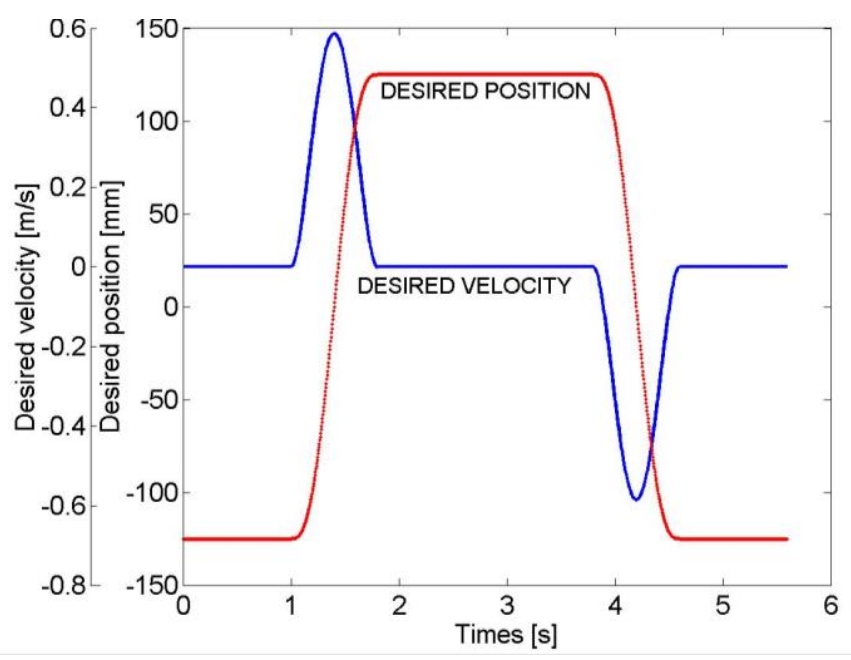

a/ Desired position and velocity

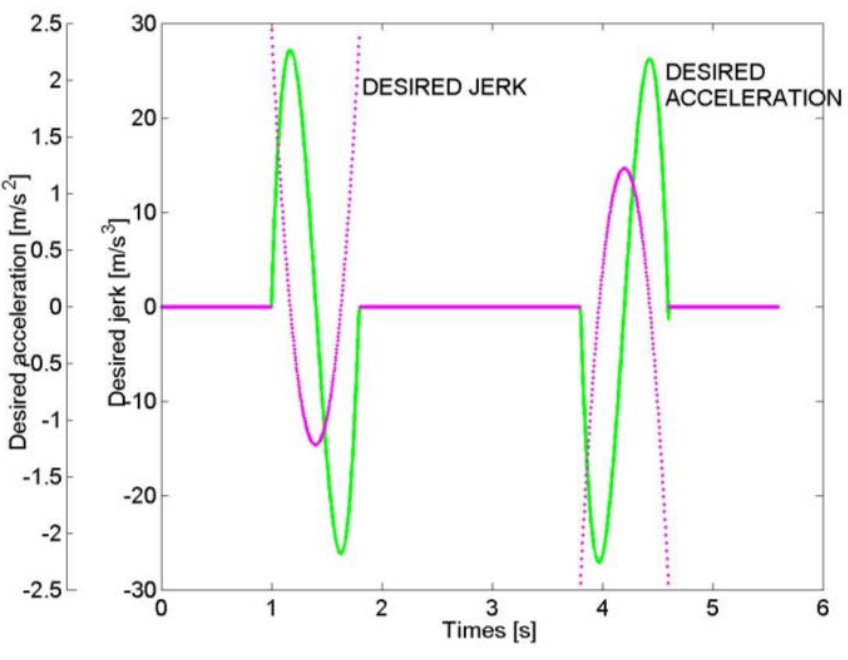

Desired acceleration and jerk

Figure 5: Desired trajectories for position tracking

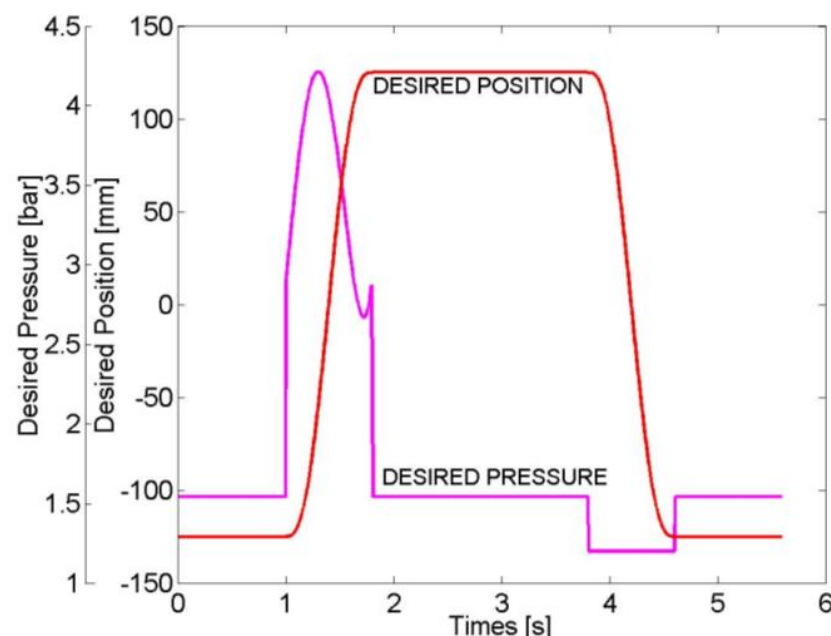

Figure 6: Desired optimized pressure in chamber $P$ 


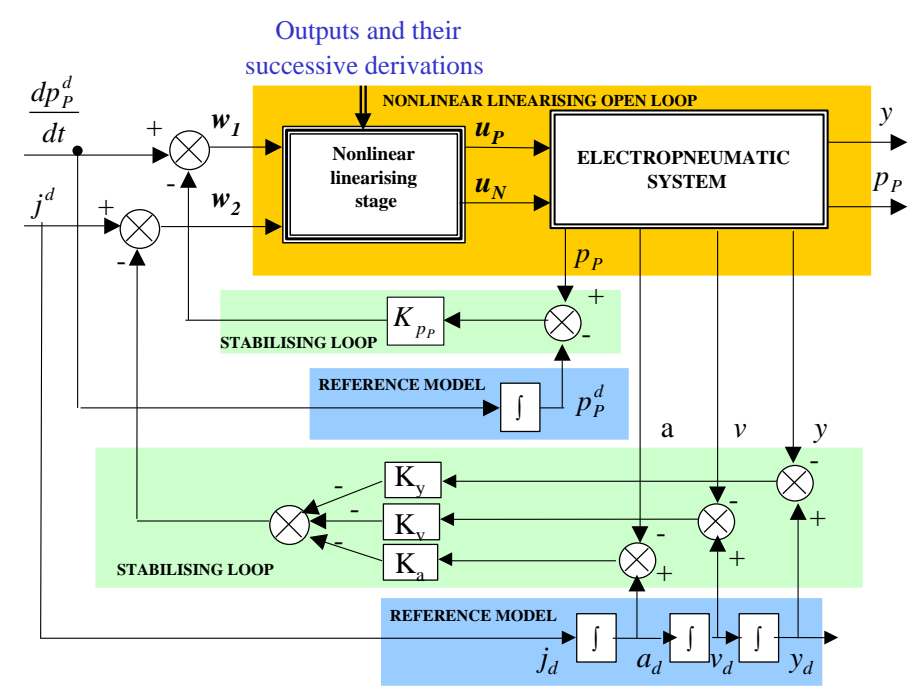

Figure 7: Principle of nonlinear multivariable control law

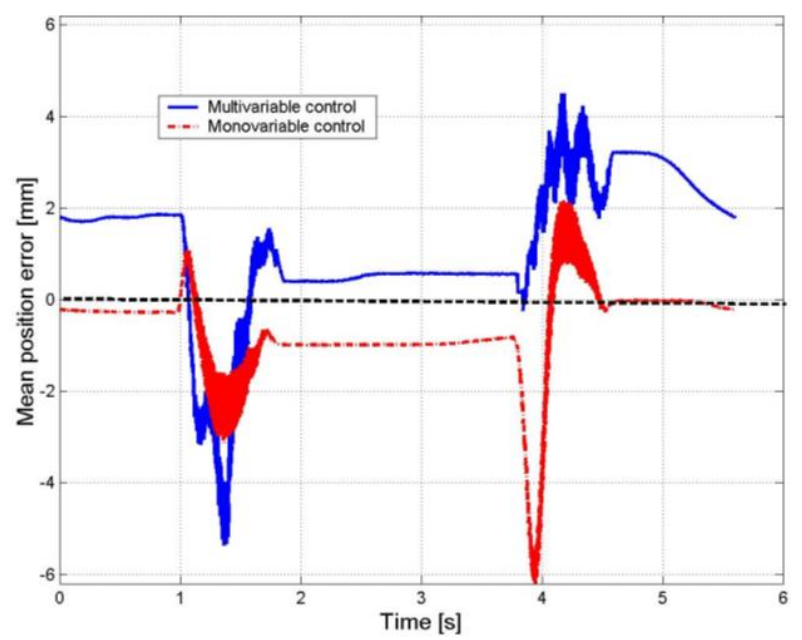

a/ Mean error in position

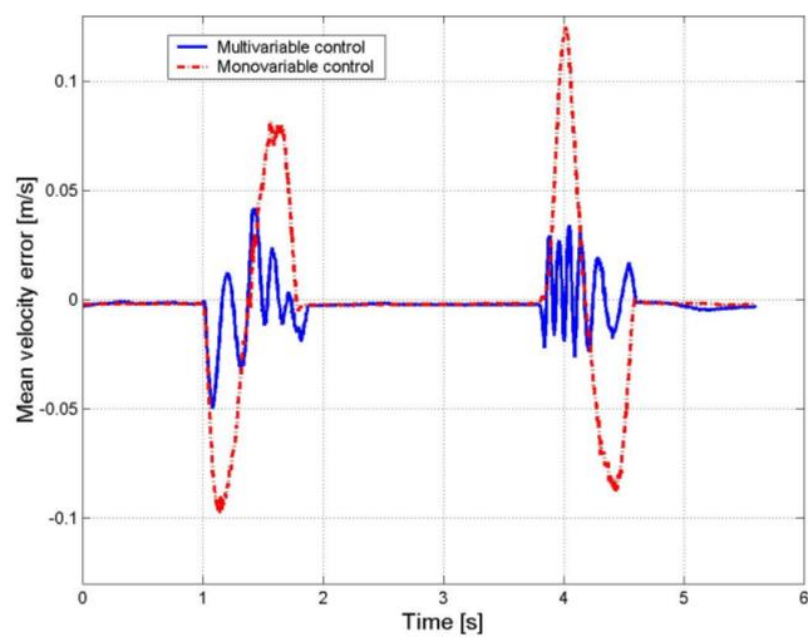

b/ Mean error in velocity

Figure 8: Mean error in position and velocity with monovariable and multivariable control laws

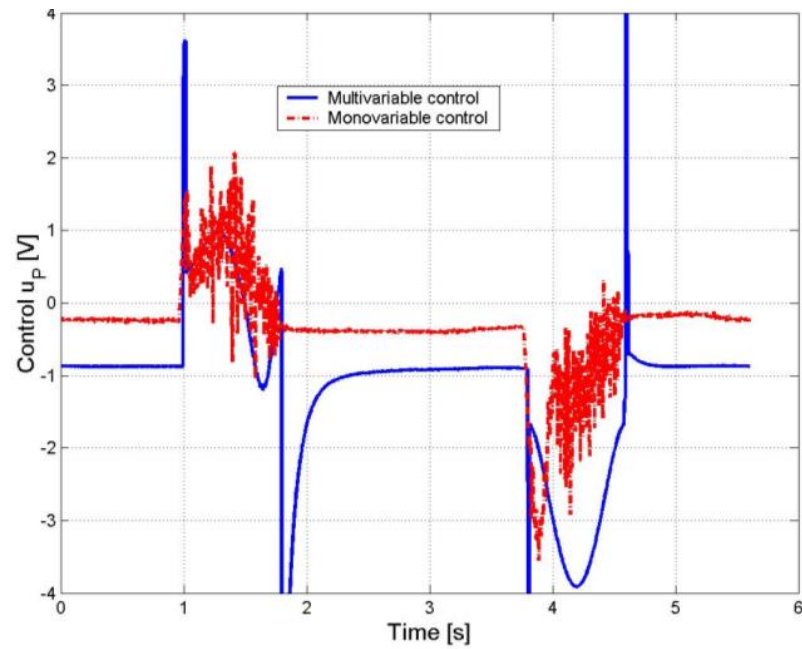

a/ Control signal $u_{P}$

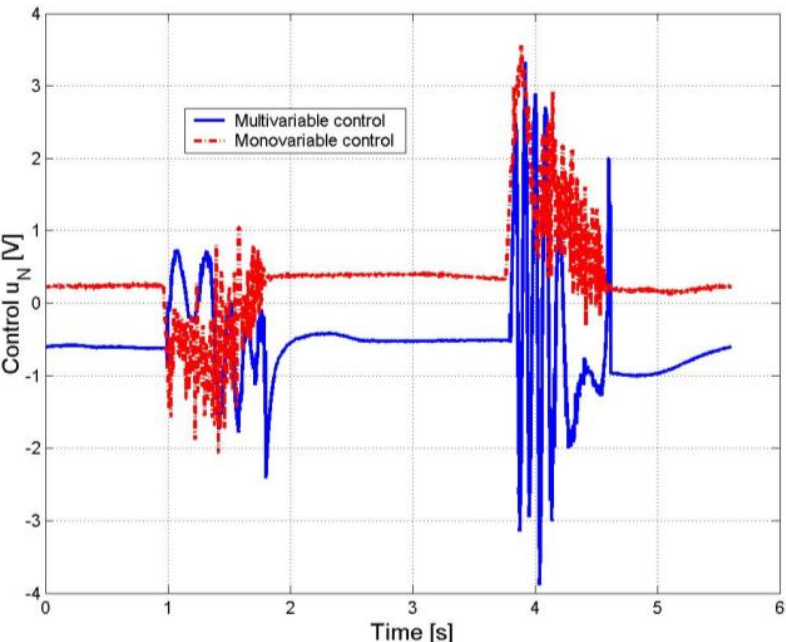

b/ Control signal $u_{N}$

Figure 9: Control signals $u_{P}$ and $u_{N}$ with monovariable and multivariable control laws 


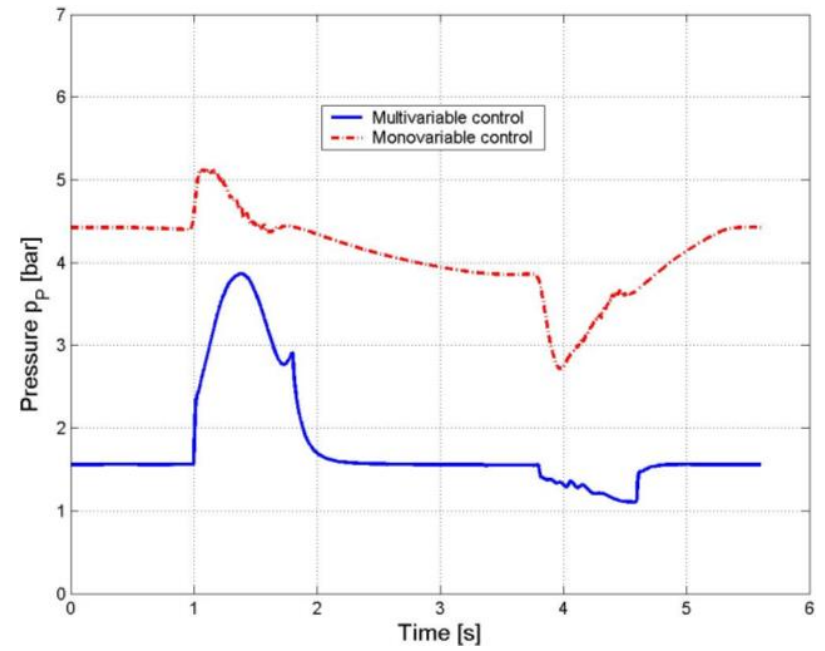

a/ Pressure $p_{P}$

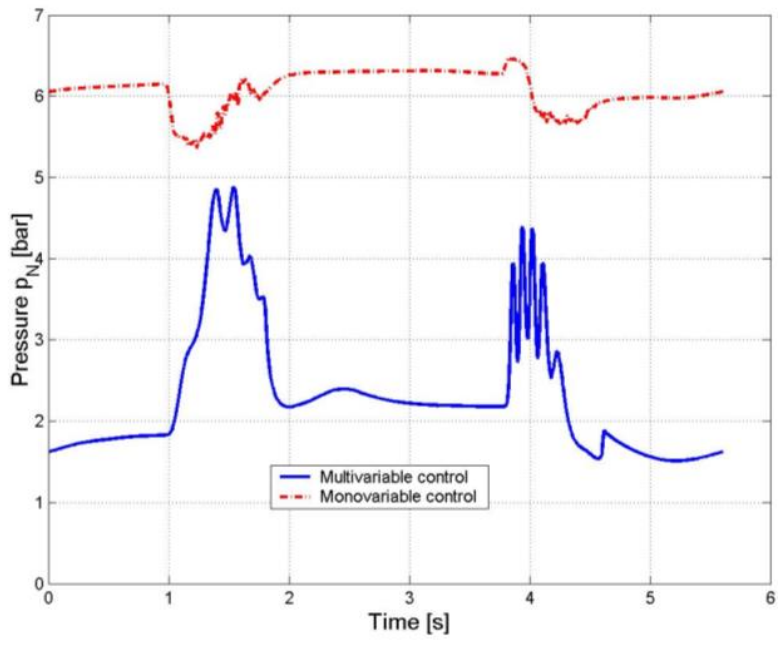

b/ Pressure $p_{N}$

Figure 10: Pressure $p_{P}$ and $p_{N}$ with monovariable and multivariable control laws

\begin{tabular}{|cccccc|}
\hline Control strategy & $\begin{array}{c}\text { Mean position } \\
\text { error }\end{array}$ & $\begin{array}{c}\text { Maximum position } \\
\text { error }\end{array}$ & $\begin{array}{c}\text { Mean standard } \\
\text { deviation in static } \\
\text { stage }\end{array}$ & $\begin{array}{c}\text { Mean standard } \\
\text { deviation in } \\
\text { dynamic stage }\end{array}$ & $\begin{array}{c}\text { Maximum standard } \\
\text { deviation }\end{array}$ \\
\hline Monovariable & 0.85 & 6.21 & 0.06 & 0.14 & 0.31 \\
\hline Multivariable & 1.59 & 5.35 & 0.48 & 0.56 & 2.98 \\
\hline
\end{tabular}

Table 1: Experimental results in position [mm]

\begin{tabular}{|cccccc|}
\hline Control strategy & $\begin{array}{c}\text { Mean velocity } \\
\text { error }\end{array}$ & $\begin{array}{c}\text { Maximum velocity } \\
\text { error }\end{array}$ & $\begin{array}{c}\text { Mean standard } \\
\text { deviation in static } \\
\text { stage }\end{array}$ & $\begin{array}{c}\text { Mean standard } \\
\text { deviation in } \\
\text { dynamic stage }\end{array}$ & $\begin{array}{c}\text { Maximum standard } \\
\text { deviation }\end{array}$ \\
\hline Monovariable & 16 & 120 & 9 & 21 & 71 \\
\hline Multivariable & 6 & 40 & 4.3 & 10 & 38 \\
\hline
\end{tabular}

Table 2: Experimental results in velocity $[\mathrm{mm} / \mathrm{s}]$ 